\title{
Effect of water temperature on the hydrolysis of two absorbable sutures used in fish surgery
}

\author{
Sarah A. Cannizzo ${ }^{\mathrm{ab} *}$, Simon C. Roe ${ }^{\mathrm{a}}$, Craig A. Harms ${ }^{\mathrm{ab}}$, and Michael K. Stoskopf ${ }^{\mathrm{ab}}$ \\ ${ }^{a}$ Department of Clinical Sciences, College of Veterinary Medicine, North Carolina State University, 1060 \\ William Moore Drive, Raleigh, NC 27607, USA, ${ }^{b}$ Environmental Medicine Consortium and Center for \\ Marine Sciences and Technology, North Carolina State University, 303 College Circle, Morehead City, \\ NC 28557, USA \\ *sacanniz@ncsu.edu
}

\begin{abstract}
Persistence of absorbable sutures in fishes in waters below $10{ }^{\circ} \mathrm{C}$ affects surgical decisions including approach, closure strategy, and suture selection. We hypothesized that the rate of suture hydrolysis would vary directly with water temperature. Two absorbable monofilament 3-0 suture materials used in fish surgery, poliglecaprone (Monocryl ${ }^{\mathrm{TM}}$ ) and polyglyconate $\left(\operatorname{Maxon}^{\mathrm{TM}}\right)$, were evaluated. The maximum tensile load (strength) was measured for suture loops $(n=6)$ maintained in filtered city water for $2,4,6$, or 8 weeks at 4,25 , or $37^{\circ} \mathrm{C}$. For Maxon ${ }^{\mathrm{TM}}$ at 4 or $25^{\circ} \mathrm{C}$, tensile strength did not decrease over time. However, for Monocryl ${ }^{\mathrm{TM}}$ at $4{ }^{\circ} \mathrm{C}, 2-, 4-$, and 8-week loops were stronger than baseline loops. At $25^{\circ} \mathrm{C}$, tensile strength of the suture material declined after 2 weeks. Also, at $37^{\circ} \mathrm{C}$, the optimal design temperature for both suture materials, the strength of Maxon ${ }^{\mathrm{TM}}$ decreased at 6 and 8 weeks. Two 4 -week loops of Monocryl ${ }^{\mathrm{TM}}$ disintegrated when handled, and after 6 and 8 weeks, all were untestable. This study confirms that absorbable sutures lose strength more slowly at ambient temperatures lower than the optimal design temperature (e.g., human body temperature) and will likely be retained longer in fishes living in waters below $25^{\circ} \mathrm{C}$.
\end{abstract} Citation: Cannizzo SA, Roe SC, Harms CA
and Stoskopf MK. 20I6. Effect of water temperature on the hydrolysis of two absorbable sutures used in fish surgery. FACETS 1: 44-54. doi: 10.1 139/ facets-2016-0006

Editor: Steven Cooke

Received: January 29, 2016

Accepted: March 16, 2016

Published: May 12, 2016

Copyright: (C) 2016 Cannizzo et al. This work is licensed under a Creative Commons Attribution 4.0 International License (CC BY 4.0), which permits unrestricted use, distribution, and reproduction in any medium, provided the original author(s) and source are credited.

Competing interests: The author(s) have declared that no competing interests exist.

Published by: Canadian Science Publishing
Key words: Fish surgery, absorbable suture, $\operatorname{Maxon}^{\mathrm{TM}}$, Monocryl ${ }^{\mathrm{TM}}$, tensile strength, water temperature

\section{Introduction}

In the same way as terrestrial mammals, fish also undergo surgical procedures, such as internal telemetry implantation; removal, evaluation, or biopsy of internal and external organs; and removal of foreign materials (Harms and Lewbart 2000). Suture materials designed for human or other terrestrial animal surgery are commonly used for routine fish surgery, but in radically different environments, performance characteristics of materials may differ. It is important to understand these differences to make informed choices in designing surgical protocols. This is particularly important for surgical procedures in poikilotherms because the variation in ambient environmental temperature may impact the performance of the suture materials. Unfortunately, useful information on suture performance related to temperature is scant in the literature available on fish surgery (Cooke et al. 2011).

Synthetic absorbable sutures are degraded by hydrolysis, which begins in the amorphous regions of the polymers where water has immediate access to chemical bonds (Fischer et al. 1973; Chu 1981; 
Tomihata et al. 2001). Breakdown of the amorphous region exposes the dense crystalline regions to water, which allows hydrolysis to progress to these regions. Also, biodegradation of suture proceeds in two stages. First, loss of strength occurs, influenced by the chemical structure of the polymer (Chu 1997; Hong et al. 2006). Then, it is followed by degradation of the crystalline structure, which influences absorption or loss of mass.

Hydrolysis is a temperature-dependent reaction, and therefore, increasing temperature increases the speed at which synthetic absorbable sutures lose tensile strength (Reed and Gilding 1981). In observational studies of transmitter retention in hybrid striped bass (Morone saxatilis $\times$ Morone chrysops) and Chinook salmon (Oncorhynchus tshawytscha), conducted on fish held in two different temperature regimes, more sutures were retained at lower temperatures (Walsh et al. 2000; Deters et al. 2010). In Chinook salmon, the difference in suture retention between the two temperature groups was reduced after a month. It has also been reported that absorbable suture remains in the tissue of fish longer than the time needed for the tissue to heal (Gilliland 1994; Walsh et al. 2000). Despite these observations on suture retention, we are unaware of any studies that describe what happens to the tensile strength of these suture materials when environmental and patient body temperatures are decreased.

We hypothesized that synthetic absorbable sutures maintain tensile strength longer at ambient water temperatures lower than the optimal design temperature (human body temperature of $37^{\circ} \mathrm{C}$ ). To investigate this hypothesis, we created knotted loops from two synthetic absorbable suture materials, maintained them at 4,25 , or $37^{\circ} \mathrm{C}$ for $2,4,6$, or 8 weeks, and then measured their tensile failure load, as an indicator of suture degradation (Freudenberg et al. 2004).

\section{Materials and methods}

\section{Suture materials}

Two absorbable, synthetic, monofilament suture materials designed for human use, but known to be used in fish surgeries, polyglyconate (Maxon ${ }^{\mathrm{TM}}$, Medtronic Minimally Invasive Therapies, Minneapolis, MN) and poliglecaprone 25 (Monocryl $^{\mathrm{TM}}$, Ethicon, Somerville, NJ), in size 3-0 (2.0 metric) were evaluated. All suture materials were in date at the time of the project.

\section{Preparation of suture loops}

Suture loops were formed around a plastic cylinder (21 mm in diameter) with two square knots (4 throws). One operator, a board-certified veterinary surgeon (SCR), tied all suture loops. The suture ends were cut to $3 \mathrm{~mm}$. Suture material was alternated after the completion of each package. The loops were placed, in no particular order, into glass Petri dishes until each Petri dish had six loops of the same suture type $(n=6)$ as illustrated in Fig. 1. Suture loops for each time period were tied in the same session. Non-sterile nitrile gloves were used for all suture handling.

\section{Maintenance of suture loops}

Suture loops were held in water processed for public consumption by the City of Raleigh, NC. The water was stored for at least $24 \mathrm{~h}$ and then filtered with activated charcoal. All water for the project was collected at one time and stored in a sealed, plastic carboy, which was stored on the counter in the laboratory at room temperature until used. Forty milliliters of water was added to each glass Petri dish, and each dish was sealed with Parafilm ${ }^{\circledast}$ (Bemis Company, Inc., Neenah, WI). The dishes were maintained in an incubator set for 4,25 , or $37^{\circ} \mathrm{C}$, for $2,4,6$, or 8 weeks. The two lower temperatures $\left(4\right.$ and $\left.25^{\circ} \mathrm{C}\right)$ were selected to represent potential ambient temperatures for cold-water and temperate to tropical fishes, respectively. The higher temperature $\left(37^{\circ} \mathrm{C}\right)$ was selected to 


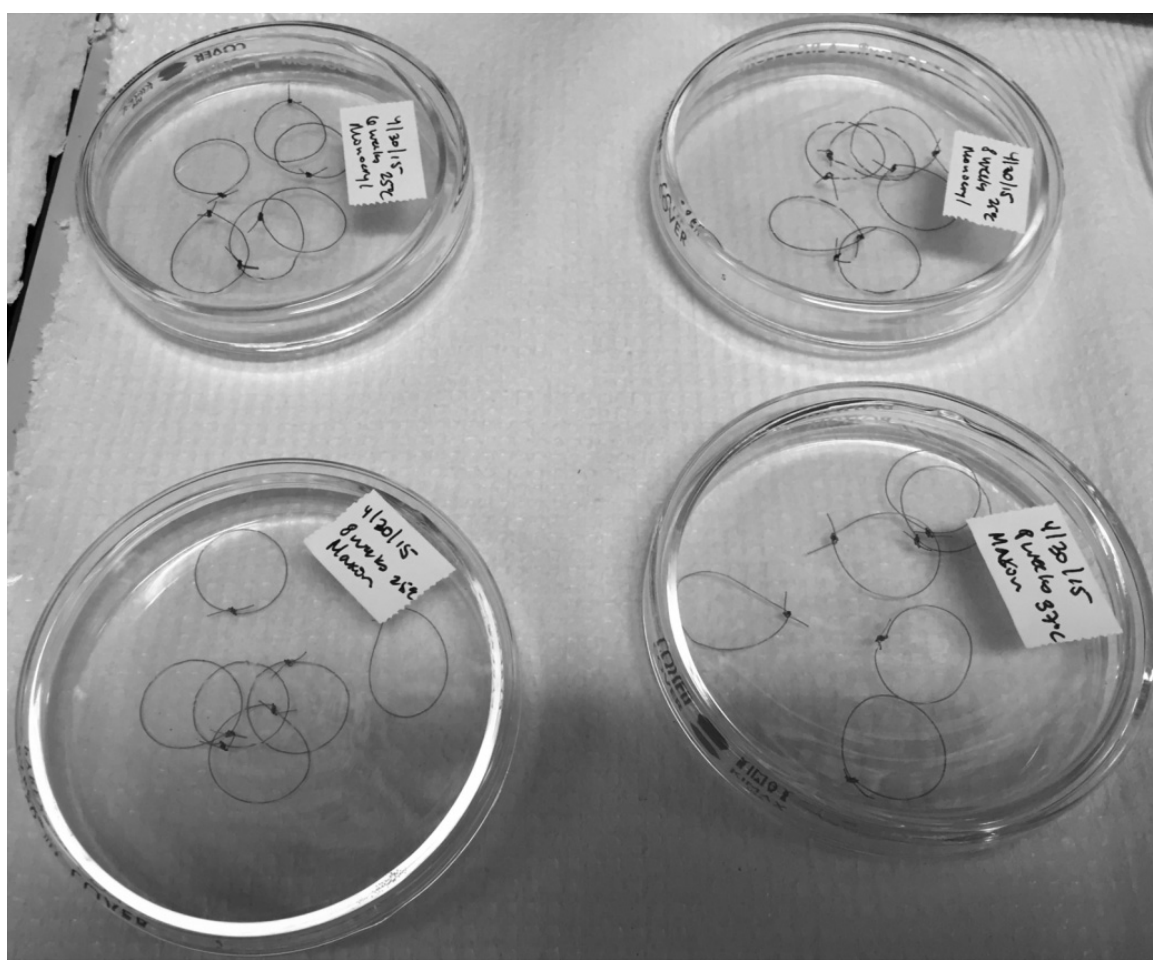

Fig. 1. Suture loops in Petri dishes before placement in incubators. Monocryl ${ }^{\mathrm{TM}}$ loops are at the top of the image and Maxon ${ }^{\mathrm{TM}}$ loops are at the bottom.

represent the internal temperature of mammalian tissues for which the suture materials were designed. Incubator external temperature displays were monitored daily, and a temperature logger (LogTag Recorders, Auckland, New Zealand) remained in each incubator for the duration of the study period. The temperature in the $37^{\circ} \mathrm{C}$ incubator ranged from 36.4 to $36.7^{\circ} \mathrm{C}$ with an average temperature of $36.7^{\circ} \mathrm{C}$ for the study period. Also, the temperature in the $25^{\circ} \mathrm{C}$ incubator ranged from 25.1 to $25.6^{\circ} \mathrm{C}$ with an average temperature of $25.3^{\circ} \mathrm{C}$ for the study period. However, the temperature in the $4{ }^{\circ} \mathrm{C}$ incubator ranged from 3.5 to $3.9^{\circ} \mathrm{C}$ with an average temperature of $3.7^{\circ} \mathrm{C}$ for the study period.

Baseline loops ( 0 weeks; $n=6$ for each suture material), representing moistened fresh suture material from the package, were bathed in an aliquot of the same source water at room temperature for $5 \mathrm{~h}$ before being tested.

\section{Mechanical testing}

At the end of each time period, intact loops were tested to failure using a tabletop test stand (SH-220, Imada, Inc., Northbrook, IL) by the same operator (SAC) as illustrated in Fig. 2. A metal hook was attached to the remote sensor of a digital force gauge (ZPS-DPU-220, Imada, Inc., Northbrook, IL) that was mounted on the test stand. A second metal hook was attached to the end of the test stand directly opposite to the first hook. Each suture loop was placed over the two metal hooks, which were moved apart by turning the hand wheel of the test stand until the suture broke or untied. Suture loops were pulled apart to failure at a median rate of $2.8 \mathrm{~mm} \mathrm{~s}^{-1}$ (lower quartile: $2.7 \mathrm{~mm} \mathrm{~s}^{-1}$; upper quartile $2.9 \mathrm{~mm} \mathrm{~s}^{-1}$ ). The mode of failure-untying or breaking — was recorded for each loop. 

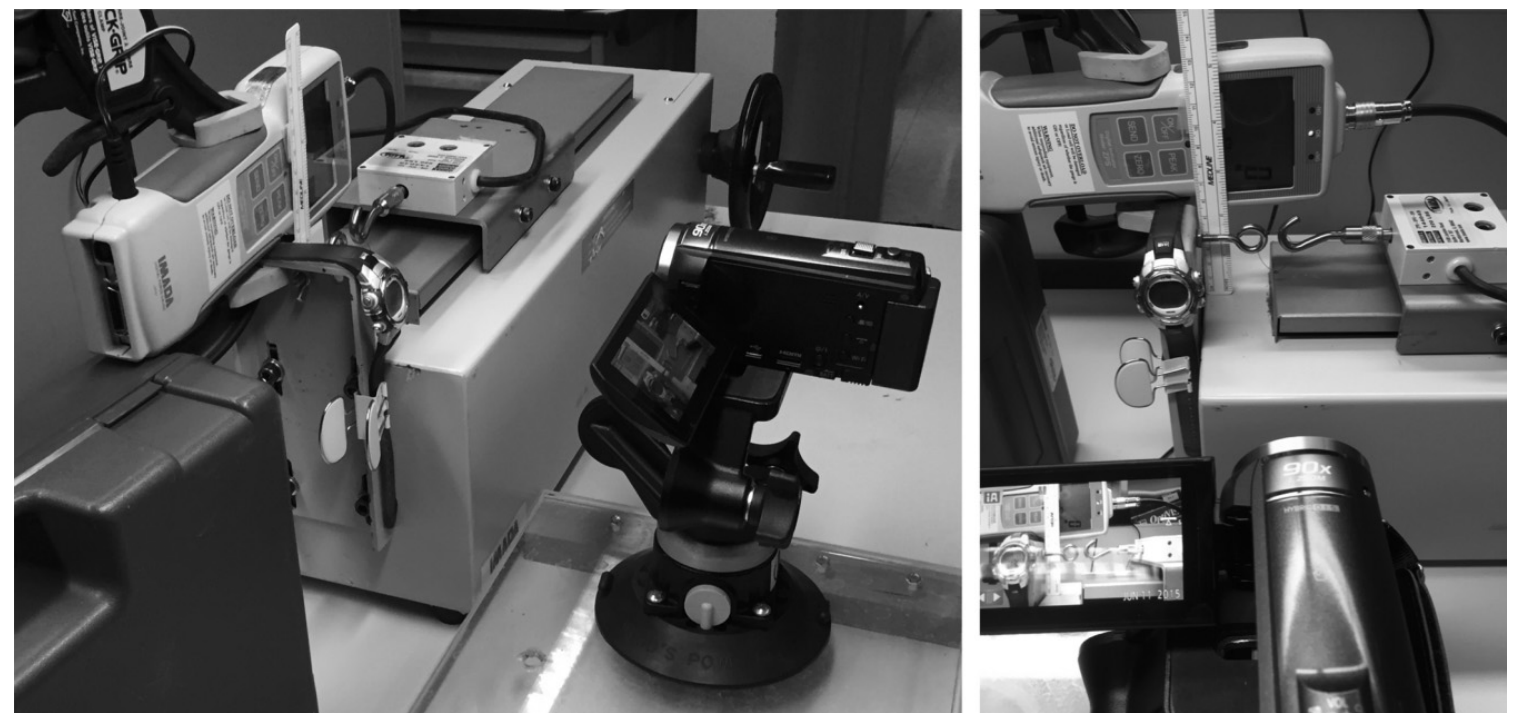

Fig. 2. Load cell with digital force gauge, stopwatch, scale bar, hand wheel test stand, and video camera.

Each test was videotaped with a high definition video camera (Panasonic Corp., Osaka, Japan). A stopwatch (Timex Group, Middelbury, CT) and a scale bar were included in the video image to provide time data and to enable image calibration. Two images were captured from each video for data collection using the software included with the camera (HD Writer LE 2.1, Panasonic Corp., Osaka, Japan). The first image corresponded to the position of the hooks at which the tension in the suture loop changed from 1 to $2 \mathrm{~N}$. This was designated as the start of each test. Initial time in hundredths of a second was recorded. The initial distance between the two metal hooks was measured from this image using the image analysis software (ImageJ version 1.48, Wayne Rasband, National Institutes of Health, Bethesda, MD) and converted to millimeters $(\mathrm{mm})$ using a pixel measurement of $30.0 \mathrm{~mm}$ on the scale bar for calibration. The scale bar was in the same plane as the two metal hooks to eliminate magnification in measuring the distance between the hooks. The second image was captured from the video frame that corresponded to the maximum force, or tensile failure load, in Newtons (N). Time was recorded, and the distance between the two hooks was measured. Stiffness $(\mathrm{N} / \mathrm{mm})$ was calculated by dividing the tensile failure load by the difference between the initial and final distances between the metal hooks.

For each time period, suture loops were tested in an order derived by a pseudo-random number generator (Microsoft ${ }^{\circledR}$ Excel $^{\circledR}$ for Mac 2011, Version 14.4.4, Microsoft, Redmond, WA).

\section{Statistical analysis}

Tensile failure load and stiffness data were tested for normality using the Shapiro-Wilk test (JMP Pro, Version 12.0.1, SAS, Cary, NC). As not all data were normally distributed, nonparametric statistics were used. For each suture type at a temperature (e.g., $\operatorname{Maxon}^{\mathrm{TM}}$ at $4{ }^{\circ} \mathrm{C}$ ), differences in tensile failure load and stiffness values were compared to a baseline (suture loops soaked in water at room temperature for $5 \mathrm{~h}$ ) and compared over time with Kruskal-Wallis tests (JMP Pro, Version 12.0.1, SAS, Cary, NC). Wilcoxon Each Pair post hoc tests were performed to determine significant differences between the time points and the baselines and between each time point (JMP Pro, Version 12.0.1, SAS, Cary, NC). Statistical significance was set at $p<0.05$. 


\section{Results}

\section{Knots}

No knots untied while the suture loops were maintained in Petri dishes. The total number of suture loops in the study was 156, and 142 loops were testable. Nine percent (14/156) of loops broke before they could be tested. These loops included two Monocryl ${ }^{\mathrm{TM}}$ loops maintained at $37^{\circ} \mathrm{C}$ for 4 weeks and all Monocryl ${ }^{\mathrm{TM}}$ loops maintained at $37^{\circ} \mathrm{C}$ for 6 and 8 weeks. The two 4 -week loops broke on the test stand before any load was applied. The $37^{\circ} \mathrm{C}$ loops maintained for 6 and 8 weeks disintegrated immediately upon handling.

For the 142 loops that could be tested, 78\% (111/142) of loops broke and 22\% (31/142) of loops untied, including all knots in the baseline group that soaked for $5 \mathrm{~h}$. Of the 77 broken loops that were examined, 67 loops broke adjacent to the knot and 10 loops broke in a location away from the knot.

\section{Tensile failure load}

Tensile failure loads are represented with box-whisker plots as shown in Fig. 3. There were no differences in tensile failure loads over time for Maxon ${ }^{\mathrm{TM}}$ at $4{ }^{\circ} \mathrm{C}(p=0.12)$. At $25^{\circ} \mathrm{C}$, the baseline (0 week) loops (median $28.5 \mathrm{~N}$ ) were weaker than the loops maintained for 2 (median $54 \mathrm{~N}$ ), $4($ median $50 \mathrm{~N}), 6($ median $48 \mathrm{~N})$, and 8 weeks (median $50 \mathrm{~N})$. At $37^{\circ} \mathrm{C}$, the baseline loops were weaker than the loops maintained for 2 (median $50 \mathrm{~N}$ ) and 4 weeks (median $48 \mathrm{~N}$ ), but stronger than the 8-week loops (median $15 \mathrm{~N}$ ). Furthermore, there were no significant differences between the baseline and the 6-week loops at $37^{\circ} \mathrm{C}$.

For Monocryl $\mathrm{l}^{\mathrm{TM}}$ at $4{ }^{\circ} \mathrm{C}$, the baseline loops (median $16.5 \mathrm{~N}$ ) were weaker than the loops maintained at $2($ median $24 \mathrm{~N}), 4($ median $30.5 \mathrm{~N}$ ), and 8 weeks (median $30.5 \mathrm{~N})$. For Monocryl ${ }^{\mathrm{TM}}$ loops maintained at $25^{\circ} \mathrm{C}$, the baseline loops were weaker than the loops maintained at 2 (median $41 \mathrm{~N}$ ), 4 (median $36.5 \mathrm{~N}$ ), and 6 weeks (median $28 \mathrm{~N}$ ). By 8 weeks (median $12.5 \mathrm{~N}$ ), there were no differences compared to the baseline. At $37^{\circ} \mathrm{C}$, 2-week loops (median $25.5 \mathrm{~N}$ ) were stronger than the baseline loops and the 4 -week loops $(2 \mathrm{~N})$. Also, the baseline loops were stronger than the 4 -week loops. At $37^{\circ} \mathrm{C}$, the 6 -week and 8-week loops were not testable.

\section{Stiffness}

Stiffness values are represented with box-whisker plots as shown in Fig. 4. For Maxon ${ }^{\mathrm{TM}}$, there were no differences in stiffness at $4{ }^{\circ} \mathrm{C}(p=0.05)$. Also, there were no differences in stiffness for Monocryl $^{\mathrm{TM}}$ at $4(p=0.53)$ or $37^{\circ} \mathrm{C}(p=0.15)$. However, for Monocryl ${ }^{\mathrm{TM}}$ at $37^{\circ} \mathrm{C}$, no stiffness values could be calculated for $4-8$ weeks because the loops failed without displacement at 4 weeks and the loops were untestable at 6 and 8 weeks.

\section{Discussion}

Our results support the hypothesis that synthetic absorbable suture materials maintain tensile strength for a longer duration when exposed to ambient water temperatures lower than their designed use $\left(37^{\circ} \mathrm{C}\right)$ compared to exposure at this optimal design temperature. Therefore, suture material that is designed to be absorbable in humans (at $37^{\circ} \mathrm{C}$ ) should not automatically be regarded as absorbable in fish and other poikilotherms, such as amphibians, inhabiting waters cooler than $37^{\circ} \mathrm{C}$. When these types of suture materials are used in fish under managed care, it is advisable to remove the sutures when the incisions have healed to minimize inflammation that can be associated with suture material (Hurty et al. 2002; Deters et al. 2010). Inflammation can lead to wound dehiscence, which, in the case of surgically placed transmitters, could lead to transmitter loss (Deters et al. 2010). For projects involving fish that will not be recaptured, suture retention to the point of sloughing (not absorption) 


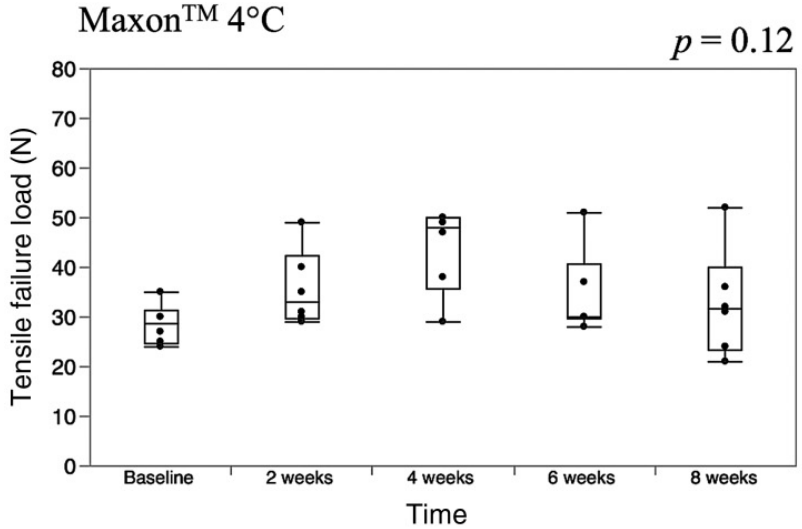

\section{Monocryl $1^{\mathrm{TM}} 4^{\circ} \mathrm{C}$}

$p<0.05$
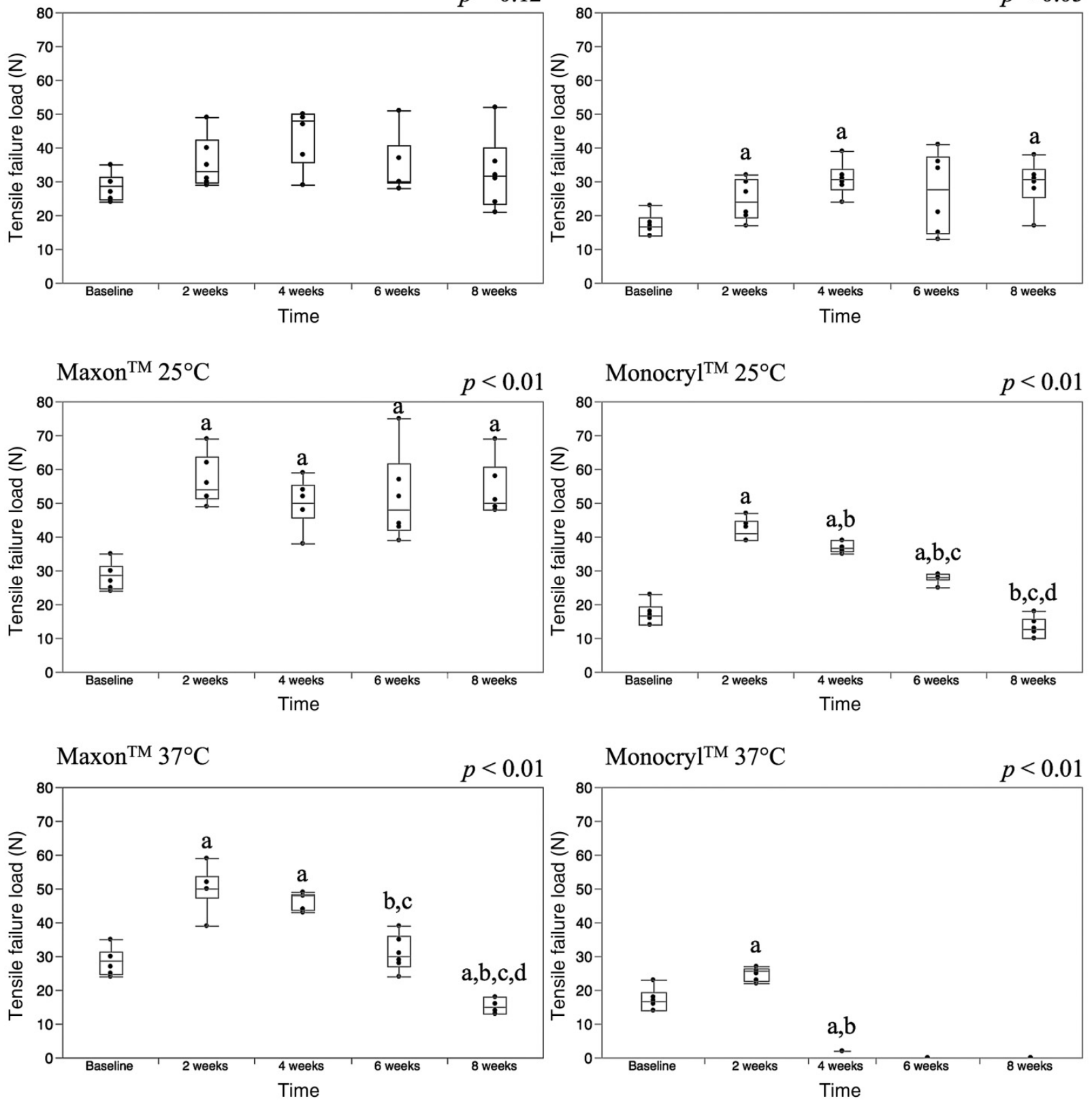

Fig. 3. Box-whisker plots of tensile failure load (N) over time for Maxon ${ }^{\mathrm{TM}}$ and Monocryl ${ }^{\mathrm{TM}}$ at the three study temperatures, 4,25 , and $37^{\circ} \mathrm{C}$. Monocryl $^{\mathrm{TM}}$ at $37{ }^{\circ} \mathrm{C}$ disintegrated after 4 weeks and could not be tested. For all plots, the lower and upper horizontal lines making up the box represent the lower and upper quartiles, respectively, and the horizontal line in the box represents the median. The lower and upper horizontal lines below and above the box represent the 10th and 90th percentiles respectively. The black dots represent data points. The $p$-values for a suture type at a temperature are included in the upper right corner of each box plot. The letters above the each box plot represent significant differences $(p<0.05)$ compared to the baseline (a), 2 weeks (b), 4 weeks (c), and 6 weeks (d). 

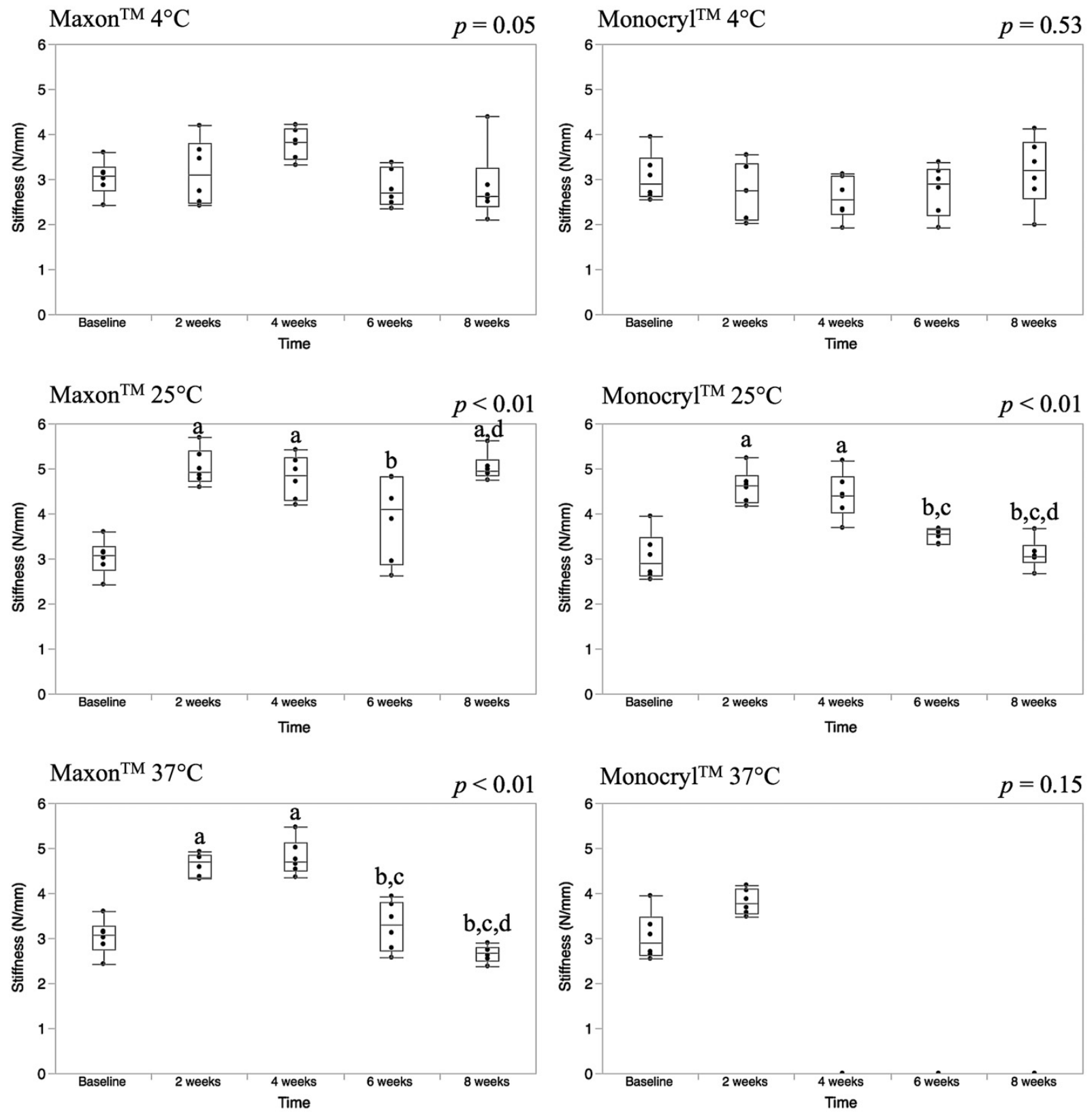

Fig. 4. Box-whisker plots of stiffness $(\mathrm{N} / \mathrm{mm})$ over time for Maxon ${ }^{\mathrm{TM}}$ and Monocryl ${ }^{\mathrm{TM}}$ at the three study temperatures, 4,25 , and $37^{\circ} \mathrm{C}$. For Monocryl ${ }^{\mathrm{TM}}$ at $37^{\circ} \mathrm{C}$, no stiffness values could be calculated for $4-8$ weeks because the loops failed without displacement at 4 weeks and the loops were untestable at 6 and 8 weeks. For all plots, the lower and upper horizontal lines making up the box represent the lower and upper quartiles, respectively, and the horizontal line in the box represents the median. The lower and upper horizontal lines below and above the box represent the 10th and 90th percentiles, respectively. The black dots represent data points. The $p$-values for a suture type at a temperature are included in the upper right corner of each box plot. The letters above the each box plot represent significant differences $(p<0.05)$ compared to the baseline (a), 2 weeks (b), 4 weeks (c), and 6 weeks (d). 
should be anticipated (Harms and Lewbart 2000). Suture retention and associated inflammation could alter fish behavior, growth, swim performance, and survivability.

Our analyses of tensile failure load at 4 and $25^{\circ} \mathrm{C}$ reveal how temperature affects suture degradation. There is a prolonged maintenance of tensile strength at 4 and $25^{\circ} \mathrm{C}$ compared to $37^{\circ} \mathrm{C}$ for both suture types, which supports our hypothesis. Maxon ${ }^{\mathrm{TM}}$ loops maintained at $4{ }^{\circ} \mathrm{C}$ lost no strength over the evaluated time period, which indicates that at low temperatures, hydrolysis of this suture type is minimal. Our results at $37^{\circ} \mathrm{C}$ are consistent with other published reports of the duration of tensile strength for Maxon $^{\mathrm{TM}}$ and Monocryl ${ }^{\mathrm{TM}}$ (Chu 1997; Outlaw et al. 1998; Freudenberg et al. 2004).

Our results differ from other studies that report baseline tensile breaking forces that are higher than the subsequent measurements over time (Outlaw et al. 1998; Freudenberg et al. 2004; de la Puerta et al. 2011). The lower forces we recorded at 0 weeks can, at least partially, be explained by the fact that all baseline loops untied instead of breaking. There were no differences in the loop creation or knot-tying processes for the baseline loops that explain this observation. Also, our baseline loops soaked for $5 \mathrm{~h}$, whereas Freudenberg et al. (2004) performed initial testing before wetting suture materials and de la Puerta et al. (2011) tested suture after exposing it to bovine serum for only 60 seconds. Testing wet suture material has been proposed to improve "skid resistance" (Pietschmann et al. 2011), and all suture materials we tested were wet, including our baseline loops.

We chose to test knotted suture loops because clinically, suture is knotted at the end of a continuous or interrupted pattern or ligated around a vessel. The failure patterns observed are expected because the knot itself and the location immediately adjacent to the knot are the weakest parts of a suture loop (Tera and Åberg 1976; von Fraunhofer and Chu 1997; Sanders et al. 2015). Loop retrieval after testing was lower than expected, but does not impact the tensile failure load or the stiffness results as these were derived from the video recordings. In response to the baseline loops untying, we created a set of loops $(n=6)$ from each suture type and added two additional throws (6 throws total). These loops failed by breaking, not untying (S. Cannizzo, personal observation, 2015). Although a small sample size, these results contrast with those of Marturello et al. (2014) who found no statistical difference in knot security with Monocryl ${ }^{\mathrm{TM}}$ when 4, 5, or 6 throws were used to form knots that were maintained at $40{ }^{\circ} \mathrm{C}$ for a minimum of $24 \mathrm{~h}$ in canine plasma; $\operatorname{Maxon}^{\mathrm{TM}}$ was not tested in the Marturello et al. (2014) study.

Ideally suture should be stiff enough to resist deformation under tension, but have sufficient flexibility to tie into a knot (Bezwada et al. 1995; de la Puerta et al. 2011). Our coldest temperature, $4{ }^{\circ} \mathrm{C}$, was associated with no changes in stiffness over time for either suture material. There were also no differences in the stiffness for Monocryl ${ }^{\mathrm{TM}}$ loops maintained at $37^{\circ} \mathrm{C}$, but stiffness could only be measured at 2 weeks at this temperature. For Maxon ${ }^{\mathrm{TM}}$, increasing the temperature increases the speed at which it loses stiffness. At $25^{\circ} \mathrm{C}$, the stiffness is constant throughout the study period, whereas it starts to decline after 4 weeks at $37^{\circ} \mathrm{C}$. For Monocryl ${ }^{\mathrm{TM}}$, stiffness is constant at $25^{\circ} \mathrm{C}$ for the first 4 weeks and then it declines for the remainder of the study period.

External facing suture and knots, as in surgical transmitter placement, are exposed to changing aqueous environments and microbial interactions in vivo. For our in vitro study, however, the loops were maintained in sealed Petri dishes for the duration of each time period to minimize handling between knot preparation and mechanical testing. The water source was the same for all the loops, and no water changes were performed. In the Petri dish for Monocry $1^{\mathrm{TM}}$ at $37^{\circ} \mathrm{C}$ for 8 weeks, there was a black, slightly raised, less than $1 \mathrm{~mm}$ in diameter contaminant on the wall of the Petri dish. This contaminant could have contributed to the degradation of the suture; however, the results at 8 weeks were consistent with those from 6 weeks and the contaminant was found on the wall of the Petri dish, not in the water. In Chung et al. (2009), there were no significant differences in tensile strength in sutures 
exposed to bacterial contamination. Synthetic absorbable suture is resistant to enzymatic breakdown because enzymes are substrate-specific. Thus, the lack of tissue exposure in this study is not likely to affect our results (Chu 1997; Freudenberg et al. 2004). Additionally, other similar in vitro suture projects have reported good correlation between in vitro and in vivo studies (Outlaw et al. 1998; Freudenberg et al. 2004). The length of our study was 8 weeks to cover the reported durations of tensile strength of the two tested suture materials in mammalian tissues (Chu 1997; Outlaw et al. 1998; Freudenberg et al. 2004). This time period could be shorter than the amount of time that absorbable suture stays in wild fish that are not re-captured.

Our hypothesis that decreasing the temperature decreases hydrolysis was confirmed for both suture materials. Therefore, when using these sutures in fish that have body and environmental temperatures less than $37^{\circ} \mathrm{C}$, surgeons should not rely on mammalian experience or expectations. This information should be considered when planning surgical procedures, such as surgical transmitter insertions and reproductive surgeries, in fish species. Synthetic absorbable sutures can still be (and are) used in fish living at temperatures lower than the suture material's optimal design temperature, but they should not be treated as absorbable in these populations. For procedures that require a longer duration of tensile strength, Maxon ${ }^{\mathrm{TM}}$ suture could be selected. If wound healing is expected to be short, Monocryl ${ }^{\mathrm{TM}}$ could be more appropriate depending on the targeted tissue. When possible, exposed sutures should be removed once incisions have healed to minimize inflammation (Gilliland 1994; Hurty et al. 2002). This inflammation could cause decreased fish performance post-operatively.

\section{Acknowledgements}

This work was supported by the Environmental Medicine Consortium, NC State University and the North Carolina Aquariums. The authors thank the following people for their support of this project: Stasia Bembenek-Bailey, Heather Broadhurst, Chris Eads, Kyle Farmer, Scott Hammer, Suzanne Kennedy-Stoskopf, Jay Levine, Cheryl Moller, Jen Nieumuth, and Kent Passingham.

\section{Author contributions}

Conceived and designed the study: SAC, SCR, CAH, MKS. Performed the experiments/collected the data: SAC, SCR. Analyzed and interpreted the data: SAC, SCR, CAH, MKS. Contributed resources: SCR, MKS. Drafted or revised the manuscript: SAC, SCR, CAH, MKS.

\section{Data accessibility statement}

All relevant data are within the paper.

\section{References}

Bezwada RS, Jamiolkowski DD, Lee I, Agarwal V, Persivale J, Trenka-Benthin S, Erneta M, Suryadevara J, Yang A, and Liu S. 1995. Monocryl ${ }^{\circledR}$ suture, a new ultra-pliable absorbable monofilament suture. Biomaterials, 16(15): 1141-1148. PMID:8562789. doi:10.1016/0142-9612(95)93577-Z.

Chu CC. 1981. An in-vitro study of the effect of buffer on the degradation of poly(glycolic acid) sutures. Journal of Biomedical Materials Research, 15(1): 19-27. PMID:6294120. doi:10.1002/ jbm.820150106.

Chu CC. 1997. Biodegradation properties. In Wound closure biomaterials and devices. Edited by CC Chu, JA von Fraunhofer, and HP Greisler. CRC Press, Boca Raton, FL. pp. 131-236. 
Chung E, McPherson N, and Grant A. 2009. Tensile strength of absorbable suture materials: In vitro analysis of the effects of $\mathrm{pH}$ and bacteria. Journal of Surgical Education, 66(4): 208-211. PMID:19896625. doi:10.1016/j.jsurg.2009.06.007.

Cooke SJ, Woodley CM, Eppard MB, Brown RS, and Nielsen JL. 2011. Advancing the surgical implantation of electronic tags in fish: A gap analysis and research agenda based on a review of trends in intracoelomic tagging effects studies. Reviews in Fish Biology and Fisheries, 21(1): 127-151. doi:10 .1007/s11160-010-9193-3.

de la Puerta B, Parsons KJ, Draper ERC, Moores AL, and Moores AP. 2011. In vitro comparison of mechanical and degradation properties of equivalent absorbable suture materials from two different manufacturers. Veterinary Surgery, 40(2): 223-227. PMID:21223313. doi:10.1111/j.1532-950X .2010.00768.x.

Deters KA, Brown RS, Carter KM, Boyd JW, Eppard MB, and Seaburg AG. 2010. Performance assessment of suture type, water temperature, and surgeon skill in juvenile Chinook salmon surgically implanted with acoustic transmitters. Transactions of the American Fisheries Society, 139(3): 888-899. doi:10.1577/T09-043.1.

Fischer EW, Sterzel HJ, and Wegner G. 1973. Investigation of the structure of solution grown crystals of lactide copolymers by means of chemical reactions. Kolloid-Zeitschrift und Zeitschrift für Polymere, 251(11): 980-990. doi:10.1007/BF01498927.

Freudenberg S, Rewerk S, Kaess M, Weiss C, Dorn-Beinecke A, and Post S. 2004. Biodegradation of absorbable sutures in body fluids and pH buffers. European Surgical Research, 36: 376-385. PMID:15591748. doi:10.1159/000081648.

Gilliland ER. 1994. Comparison of absorbable sutures used in largemouth bass liver biopsy surgery. The Progressive Fish-Culturist, 56(1): 60-61. doi:10.1577/1548-8640(1994)056<0060:COASUI $>2.3$. $\mathrm{CO} ; 2$.

Harms CA, and Lewbart GA. 2000. Surgery in fish. The Veterinary Clinics of North America: Exotic Animal Practice, 3(3): 759-774. PMID:11228930.

Hong JT, Cho NS, Yoon HS, Kim TH, Koh MS, and Kim WG. 2006. Biodegradable studies of poly(trimethylenecarbonate- $\varepsilon$-caprolactone)-block-poly(p-dioxanone), poly(dioxanone), and poly(glycolide$\varepsilon$-caprolactone) $\left(\right.$ Monocryl $^{\circledR}$ ) monofilaments. Journal of Applied Polymer Science, 102(1): 737-743. doi:10.1002/app.24440.

Hurty CA, Brazik DC, Lewbart GA, Law JM, and Sakamoto K. 2002. Evaluation of the tissue reactions in the skin and body wall of koi (Cyprinus carpio) to five suture materials. Veterinary Record, 151(11): 324-328. PMID:12356236. doi:10.1136/vr.151.11.324.

Marturello DM, McFadden MS, Bennett RA, Ragetly GR, and Horn G. 2014. Knot security and tensile strength of suture materials. Veterinary Surgery, 43(1): 73-79. PMID:24383708. doi:10.1111/ j.1532-950X.2013.12076.x.

Outlaw KK, Vela AR, and O'Leary JP. 1998. Breaking strength and diameter of absorbable sutures after in vivo exposure in the rat. The American Surgeon, 64(4): 348-354. PMID:9544148.

Pietschmann MF, Sadoghi P, Häuser E, Scharpf A, Gülecyüz MF, Schröder C, Jansson V, and Müller PE. 2011. Influence of testing conditions on primary stability of arthroscopic knot tying for 
rotator cuff repair: slippery when wet? Arthroscopy: The Journal of Arthroscopic and Related Surgery, 27(12): 1628-1636. PMID:21945675. doi:10.1016/j.arthro.2011.06.031.

Reed AM, and Gilding DK. 1981. Biodegradable polymers for use in surgery-poly(glycolic)/poly(lactic acid) homo and co-polymers: 2. In vitro degradation. Polymer, 22(4): 494-498. doi:10.1016/ 0032-3861(81)90168-3.

Sanders RE, Kearney CM, Buckley CT, Jenner F, and Brama PA. 2015. Knot security of 5 metric (USP 2) sutures: influence of knotting technique, suture material, and incubation time for 14 and 28 days in phosphate buffered saline and inflamed equine peritoneal fluid. Veterinary Surgery, 44(6): 723-730. PMID:25998193. doi:10.1111/vsu.12333.

Tera H, and Åberg C. 1976. Tensile strengths of twelve types of knot employed in surgery, using different suture materials. Acta Chirurgica Scandinavica, 142(1): 1-7. PMID:1266536.

Tomihata K, Suzuki M, and Ikada Y. 2001. The pH dependence of monofilament sutures on hydrolytic degradation. Journal of Biomedical Materials Research, 58(5): 511-518. PMID:11505425. doi:10.1002/jbm.1048.

von Fraunhofer JA and Chu CC. 1997. Mechanical properties. In Wound closure biomaterials and devices. Edited by CC Chu, JA von Fraunhofer, and HP Greisler. CRC Press, Boca Raton, FL. pp. 107-130.

Walsh MG, Bjorgo KA, and Isely J. 2000. Effects of implantation method and temperature on mortality and loss of simulated transmitters in hybrid striped bass. Transactions of the American Fisheries Society, 129(2): 539-544. doi:10.1577/1548-8659(2000)129<0539:EOIMAT>2.0.CO;2. 